\title{
ANALISIS PRODUKTIVITAS PEMBUATAN KAIN GREY DENGAN PENDEKATAN METODE AMERICAN PRODUCTIVITY CENTER DAN COBB-DOUGLAS
}

\author{
Abdul Jalal ${ }^{1}$, Helvi Kusumawati ${ }^{2}$ \\ Jurusan Teknik Industri, Fakultas Teknologi Industri, Universitas Islam Indonesia, ${ }^{1,2)}$ \\ Jl.Kaliurang Km.14,5, Sleman, Yogyakarta, 55584 \\ E-Mail:835220103@uii.ac.id
}

\begin{abstract}
PT. Primissima is a company engaged in textile Bisang, producing gray cloth that was established in 1971. The purpose of this study to determine the level of productivity with the approach of the American method Productivity Center (APC) and the Cobb-Douglas particular weaving section. Next calculate the productivity index forecast to come on the method selected is the highest. The data collected in this study consisted of data from production (output), labor, material, energy, and capital. Methods American Productivity Center (APC) was used to calculate the index of productivity, profitability index and the index of price improvement. While the Cobb-Douglas method used to calculate the coefficient of the intercept and Return to Scale. From the research conducted, the total productivity index using American Productivity Center (APC) has decreased, with a productivity index of 96.00 partially in 2009 and 2011. The profitability of the total input decreased by an average of 47.98 in partial quarterly. Total input price index improvement on average decreased partially 0.50 per quarter. The results using the method Cobb-Douglas found that inputs affect the production process is the efficiency index for 2009 was 58,997,167.96, while the year 2010 was 8.499, and in 2011 was 36,179,393.57. The use of the elasticity of input for the year 2009 amounted to -0.549 labor, material amounted to 0,062, a total energy of 0.613, and a capital of 0.093. The use of the elasticity of input for the year 2010 amounting to -0.032 use of labor, material amounted to 0.595, an energy of 0.114 , and a capital of 0.267. The use of the elasticity of input for the year 2011 amounting to -0.781 use of labor, material amounted to 0.602, an energy of 0.063 and capital.of 0.298.
\end{abstract}

Keywords : American Productivity Center (APC), Cobb-Douglas, Profitability, Labor, Material, Energy.

\section{PENDAHULUAN}

Produktivitas merupakan salah satu alternatif parameter untuk mengevaluasi kinerja yang telah dilakukan. Produktivitas juga merupakan salah satu cara yang sangat tepat dalam menilai efisiensi pemakaian sejumlah input dalam menghasilkan output tertentu. Suatu perusahaan juga perlu mengetahui produktivitasnya, agar dapat membandingkannya dengan produktivitas yang telah ditetapkan oleh manajemen. Peningkatan produktivitas haruslah melalui suatu proses yang menyangkut perencanaan, pengorganisasian, pelaksanaan serta pengendalian terhadap strategi - strategi yang telah ditetapkan.

PT. Primissima adalah salah satu industri yang bergerak di bidang tekstil. Perusahaan ini telah mengalami kenaikan dan penurunan hasil produksi pada tahun 2009 - 2011. Untuk melakukan perbaikan produktivitas, perusahaan tekstil juga menjadikan efisiensi dan efektivitas sebagai parameternya. Beberapa sektor penting di PT. Primissima adalah tenaga kerja, bahan baku, energi dan modal yang semuanya adalah faktor yang mempengaruhi pada tingkat produktivitas perusahaan.

Pada penelitian ini dilakukan analisis pengukuran tingkat produktivitas untuk mengevaluasi dan mengefisiensikan faktorfaktor produksi menggunakan American Productivity Center (APC) dan CobbDouglas. Fungsi produksi Cobb-Douglas merupakan salah satu bentuk fungsi produksi yang paling banyak dipergunakan dalam analisis produktivitas. Fungsi produksi Cobb-Douglas bersifat sederhana dan mudah 
dalam penerapannya, mampu menggambarkan keadaan skala hasil (returns to scale) apakah sedang meningkat, tetap atau menurun. Koefisien - koefisien fungsi produksi Cobb-Douglas secara langsung menggambarkan elastisitas produksi dari setiap input yang dipergunakan. Koefisien intersep dari fungsi produksi Cobb-Douglas merupakan indeks efisiensi produksi yang secara langsung menggambarkan efisiensi penggunaan input dalam menghasilkan output dari sistem produksi yang sedang dikaji. pengukuran produktivitas menggunakan model American Productivity Center (APC) akan memberikan informasi yang lebih jelas dan komprehensif tentang sumber-sumber peningkatan profitabilitas perusahaan (Gaspersz, 1998).

\section{KAJIAN LITERATUR}

Kajian mengenai analisis produktivitas telah banyak dilakukan oleh para peneliti sebelumnya. Ini menunjukkan bahwa analisis produktivitas mendapat perhatian dari banyak peneliti tentang produktivitas. Heri Suliantoro, et. al (2006) telah menggunakan metode APC untuk menganalisis produktivitas sebuah perusahaan. Hasil penelitiannya menunjukkan bahwa metode APC dapat digunakan untuk menunjukkan kondisi produktivitas perusahaan dan faktor - faktor yang mempengaruhinya. Penelitian lain yang menggunakan APC juga telah dilakukan oleh Masharyono (2012).

Metode Cobb-Douglas juga telah digunakan oleh beberapa peneliti terdahulu untuk menganalisis produktifitas. Yuliastuti Ramadhani (2011) telah menggunakan Cobb-Douglas dan Regresi Berganda untuk mengetahui efisiensi, skala dan elastisitas produksi sebuah industri. Sutrisno dan Ferry Suzanto (2012) juga telah menggunakan metode Cobb-Douglas dan berhasil mengidentifikasi skala hasil setiap proses produksi yang diteliti.
Tabel 1. Produk Benang dan Kain di PT. Primissima

\begin{tabular}{cccc}
\hline \multicolumn{4}{c}{ Produk } \\
\hline \multicolumn{2}{c}{ Benang } & \multicolumn{2}{c}{ Kain } \\
\hline Jenis & Grade & Jenis & Grade \\
$40 \mathrm{CD}$ & A & PS. 217 & A12 \\
$60 \mathrm{CM}$ & B & PS. 219 & B \\
$50 \mathrm{CM}$ & C & PS. 318 & C1 \\
& D & PS. 409 & C2 \\
& & PS. 420 & \\
& & PS. 421 & \\
& & PS. 430 & \\
\hline
\end{tabular}

\subsection{Analisis Produktifitas Menggunakan APC}

\subsubsection{Analisis Produktifitas Input}

Data yang diperlukan dalam penelitian ini adalah data output produksi, jumlah tenaga kerja, penggunaan material, penggunaan energi dan penggunaan modal. Tabel 1 menunjukkan data mengenai produk dan jenisnya yang diproduksi oleh industri yang digunakan sebagai obyek penelitian. Gambar 1 menunjukkan proses produksi di industri tersebut dan tabel 1 menunjukkan data produksi industri tersebut mulai tahun 2009 sampai denga tahun 2011. Untuk tahun 2012 sampai sekarang, data tidak tersedia, dan ini yang menjadi salah satu usulan perbaikan bagi analisis produktifitas di industri tersebut.

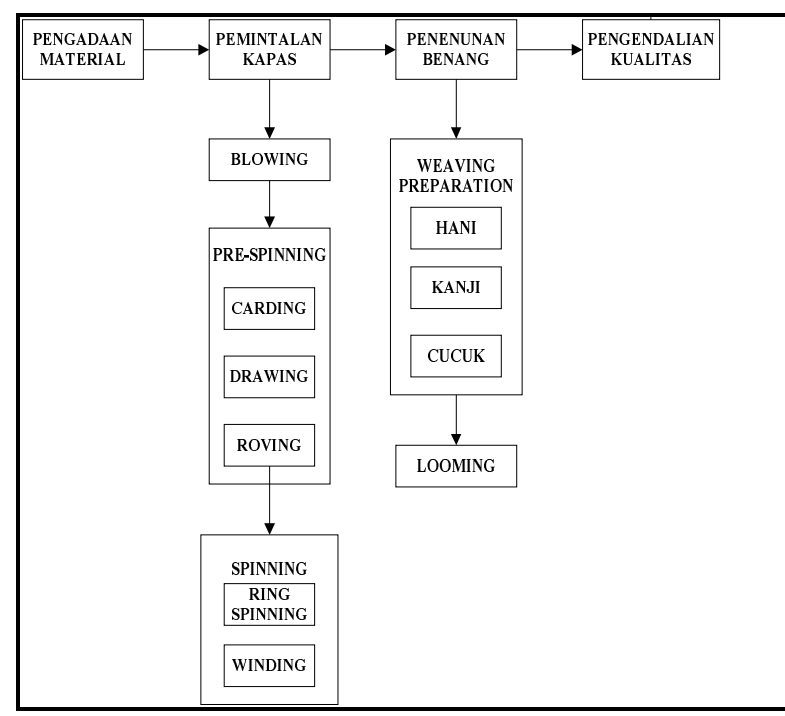

Gambar 1. Proses Produksi

di PT. Primissima. 
Tabel 2. Data Produksi Kain Grey Tahun 2009 - 2011

\begin{tabular}{cccc}
\hline \multirow{2}{*}{ Bulan } & \multicolumn{3}{c}{ Produk Kain (Meter) } \\
& Tahun 2009 & Tahun 2010 & Tahun 2011 \\
\hline Januari & $1.110 .688,19$ & $1.077 .056,68$ & $1.436 .051,11$ \\
Februari & $983.879,50$ & $1.055 .891,87$ & $1.251 .389,17$ \\
Maret & $1.096 .289,82$ & $1.067 .476,74$ & $1.396 .561,84$ \\
April & $1.024 .388,76$ & $1.116 .750,31$ & $1.325 .826,00$ \\
Mei & $1.101 .440,19$ & $1.262 .885,41$ & $1.586 .002,92$ \\
Juni & $1.215 .706,46$ & $1.291 .861,77$ & $1.297 .911,04$ \\
Juli & $1.176 .157,87$ & $1.224 .274,07$ & $1.322 .384,78$ \\
Agustus & $1.222 .823,47$ & $1.347 .330,06$ & $1.118 .936,37$ \\
September & $1.147 .108,94$ & $1.085 .116,61$ & $1.221 .003,47$ \\
Oktober & $1.160 .972,50$ & $1.415 .156,33$ & $1.325 .767,38$ \\
Nopember & $1.055 .196,09$ & $1.048 .188,37$ & $1.137 .503,93$ \\
Desember & $1.055 .196,09$ & $1.277 .535,07$ & $1.240 .559,30$ \\
\hline
\end{tabular}

Tabel 3. Indeks Output Berdasarkan Harga Konstan Tahun 2009 - 2011

\begin{tabular}{cccc}
\hline Tahun & Kuartal & $\begin{array}{c}\text { Kain Grey (O) } \\
\text { (Rupiah) }\end{array}$ & Indeks Output \\
\hline 2009 & Q1 & 32.035 .871 .652 & 1,00 \\
& Q2 & 35.842 .572 .800 & 1,12 \\
2010 & Q3 & 33.580 .399 .512 & 1,05 \\
& Q1 & 32.810 .534 .560 & 1,02 \\
& Q2 & 38.960 .269 .956 & 1,22 \\
& Q3 & 40.471 .786 .836 & 1,26 \\
& Q1 & 41.114 .693 .712 & 1,28 \\
& Q2 & 40.471 .786 .836 & 1,26 \\
& Q3 & 37.428 .739 .008 & 1,17 \\
\hline
\end{tabular}

Analisis produktifitas dilakukan per 4 bulan sekali. Ini dilakukan dengan tujuan agar kondisi industri pada saat dianalisis adalah stabil. Hasil perhitungan indeks output menggunakan metode APC, yang didasarkan pada total biaya produksi dan output yang dihasilkan adalah seperti yang ditunjukkan oleh tabel 3.
Berdasarkan data total biaya tenaga kerja (Labour / L), bahan baku (Material/ M), energi (Energy / E) dan modal (Capital / C), maka dapat dihitung indeks input industri tersebut untuk tahun 2009 - 2011 seperti yang ditunjukkan oleh tabel 4 dan tabel 5 . Gambar 2 menunjukkan pergerakan indeks input setiap tahunnya. 
Tabel 4. Data Input Berdasarkan Harga Konstan Tahun 2009 - 2011

\begin{tabular}{|c|c|c|c|c|c|c|}
\hline Thn & Kuartal & $\begin{array}{c}\text { Labour } \\
(L) \\
\text { (Rupiah) }\end{array}$ & $\begin{array}{l}\text { Material } \\
\quad(M) \\
\text { (Rupiah) }\end{array}$ & $\begin{array}{c}\text { Energy } \\
(E) \\
\text { (Rupiah) }\end{array}$ & $\begin{array}{c}\text { Capital } \\
\text { (C) } \\
\text { (Rupiah) }\end{array}$ & $\begin{array}{c}\text { Total } \\
(I) \\
\text { (Rupiah) }\end{array}$ \\
\hline \multirow[t]{3}{*}{2009} & Q1 & 1.986 .920 .000 & 20.443 .782 .149 & 3.259 .401 .979 & 6.345 .767 .524 & 64.071 .743 .304 \\
\hline & Q2 & 1.986 .920 .000 & 20.258 .506 .347 & 3.491 .191 .877 & 10.409 .410 .756 & 71.988 .601 .780 \\
\hline & Q3 & 1.986 .920 .000 & 21.865 .854 .448 & 3.262 .725 .409 & 7.115 .601 .608 & 67.811 .500 .978 \\
\hline \multirow[t]{3}{*}{2010} & Q1 & 1.795 .000 .000 & 22.052 .734 .174 & 3.151 .025 .800 & 8.460 .565 .182 & 68.269 .859 .716 \\
\hline & Q2 & 1.795 .000 .000 & 24.488 .935 .811 & 3.603 .747 .820 & 12.461 .323 .626 & 81.309 .277 .213 \\
\hline & Q3 & 1.795 .000 .000 & 23.210 .564 .361 & 3.446 .059 .433 & 9.674 .935 .141 & 78.598 .345 .770 \\
\hline \multirow[t]{3}{*}{2011} & Q1 & 1.810 .600 .000 & 24.971 .965 .748 & 3.834 .778 .592 & 17.688 .578 .166 & 89.420 .616 .217 \\
\hline & Q2 & 1.810 .600 .000 & 25.899 .156 .503 & 3.714 .872 .205 & 13.068 .214 .589 & 84.964 .630 .133 \\
\hline & Q3 & 1.810 .600 .000 & 23.303 .366 .651 & 3.161 .224 .333 & 14.276 .421 .351 & 79.980 .351 .343 \\
\hline
\end{tabular}

Tabel 5. Indeks Input Berdasarkan Harga Konstan 2009 - 2011

\begin{tabular}{ccccccc}
\hline \multirow{2}{*}{ Tahun } & & \multicolumn{5}{c}{ Indeks Input dengan Harga konstan } \\
\\
\cline { 3 - 7 } 2009 & Q1 & 1,00 & 1,00 & 1,00 & 1,00 & 1,00 \\
& Q2 & 1,00 & 0,99 & 1,07 & 1,64 & 1,12 \\
\multirow{2}{*}{2010} & Q3 & 1,00 & 1,07 & 1,00 & 1,12 & 1,06 \\
& Q1 & 0,90 & 1,08 & 0,97 & 1,33 & 1,07 \\
& Q2 & 0,90 & 1,20 & 1,11 & 1,96 & 1,27 \\
& Q3 & 0,90 & 1,06 & 1,06 & 1,36 & 1,16 \\
& Q1 & 0,91 & 1,22 & 1,18 & 2,79 & 1,40 \\
& Q2 & 0,91 & 1,27 & 1,14 & 2,06 & 1,33 \\
& Q3 & 0,91 & 1,14 & 0,97 & 2,25 & 1,25 \\
\hline
\end{tabular}

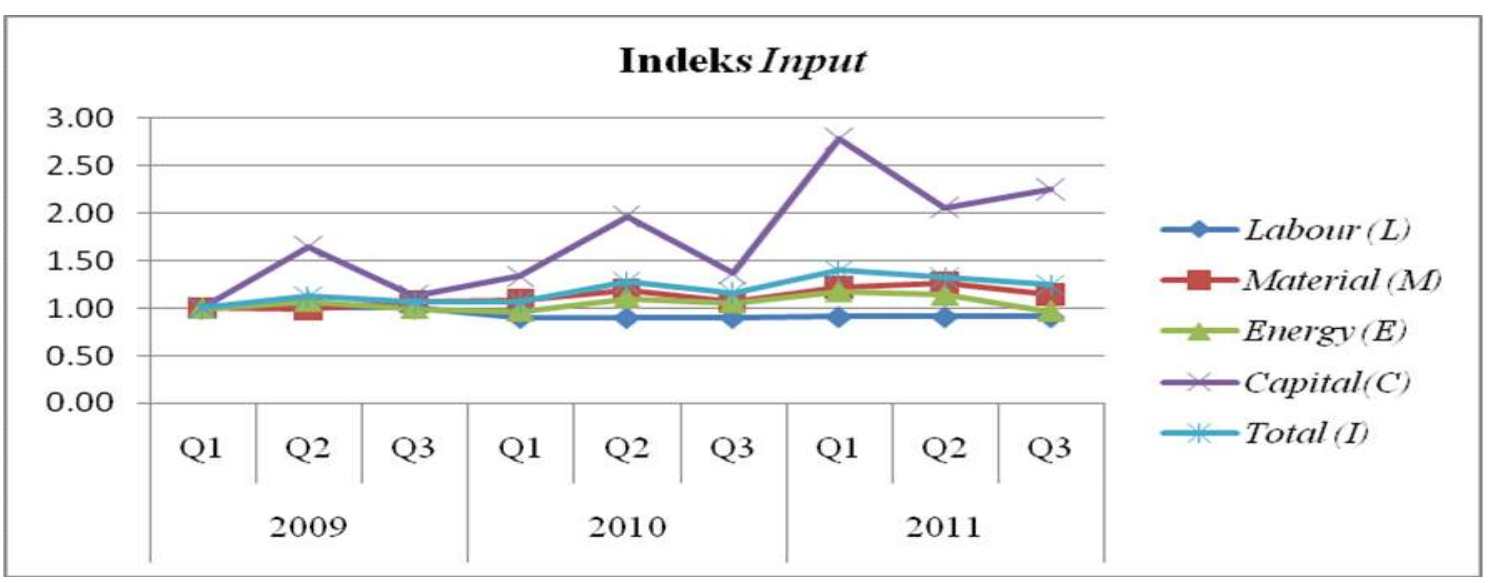

Gambar 2. Diagram Indeks Input Berdasarkan Metode APC 
Tabel 6. Produktivitas Input Berdasarkan Harga Konstan Tahun 2009 - 2011

\begin{tabular}{ccccccc}
\hline \multirow{2}{*}{ Tahun } & Kuartal & $\begin{array}{c}\text { Labour } \\
(\mathbf{P L})\end{array}$ & $\begin{array}{c}\text { Material } \\
(\mathbf{P M})\end{array}$ & $\begin{array}{c}\text { Energy } \\
(\mathbf{P E})\end{array}$ & $\begin{array}{c}\text { Capital } \\
(\mathbf{P C})\end{array}$ & $\begin{array}{c}\text { Total } \\
\text { (PI) }\end{array}$ \\
\hline \multirow{2}{*}{2009} & Q1 & 16,12 & 1,57 & 9,83 & 5,05 & 0,51 \\
& Q2 & 18,04 & 1,77 & 10,27 & 3,44 & 0,49 \\
& Q3 & 16,90 & 1,54 & 10,29 & 4,72 & 0,49 \\
2010 & Q1 & 18,28 & 1,49 & 10,41 & 3,88 & 0,47 \\
& Q2 & 21,70 & 1,59 & 10,81 & 3,13 & 0,48 \\
& Q3 & 22,55 & 1,74 & 11,74 & 4,18 & 0,52 \\
& Q1 & 22,71 & 1,65 & 10,72 & 2,32 & 0,48 \\
& Q2 & 22,35 & 1,56 & 10,89 & 3,10 & 0,47 \\
& Q3 & 20,67 & 1,61 & 11,84 & 2,62 & 0,47 \\
\hline
\end{tabular}

Tabel 7. Indeks Input Produktivitas Tahun 2009 - 2011

\begin{tabular}{ccccccc}
\hline Tahun & Kuartal & $\begin{array}{c}\text { Labor } \\
\text { (IPL) }\end{array}$ & $\begin{array}{c}\text { Material } \\
\text { (IPM) }\end{array}$ & $\begin{array}{c}\text { Energy } \\
\text { (IPE) }\end{array}$ & $\begin{array}{c}\text { Capital } \\
\text { (IPC) }\end{array}$ & $\begin{array}{c}\text { Total } \\
\text { (IPI) }\end{array}$ \\
\hline \multirow{2}{*}{2009} & Q1 & 100,00 & 100,00 & 100,00 & 100,00 & 100,00 \\
& Q2 & 111,88 & 112,91 & 104,45 & 68,21 & 96,83 \\
& Q3 & 104,82 & 98,00 & 104,71 & 93,48 & 97,46 \\
& Q1 & 113,37 & 94,95 & 105,94 & 76,82 & 93,11 \\
& Q2 & 134,62 & 101,53 & 109,99 & 61,93 & 94,55 \\
& Q3 & 139,84 & 111,27 & 119,49 & 82,86 & 101,53 \\
& Q1 & 140,84 & 105,07 & 104,17 & 46,04 & 95,09 \\
& Q2 & 138,64 & 99,72 & 110,84 & 61,35 & 93,07 \\
& Q3 & 128,21 & 102,50 & 120,46 & 51,93 & 92,37 \\
\hline
\end{tabular}

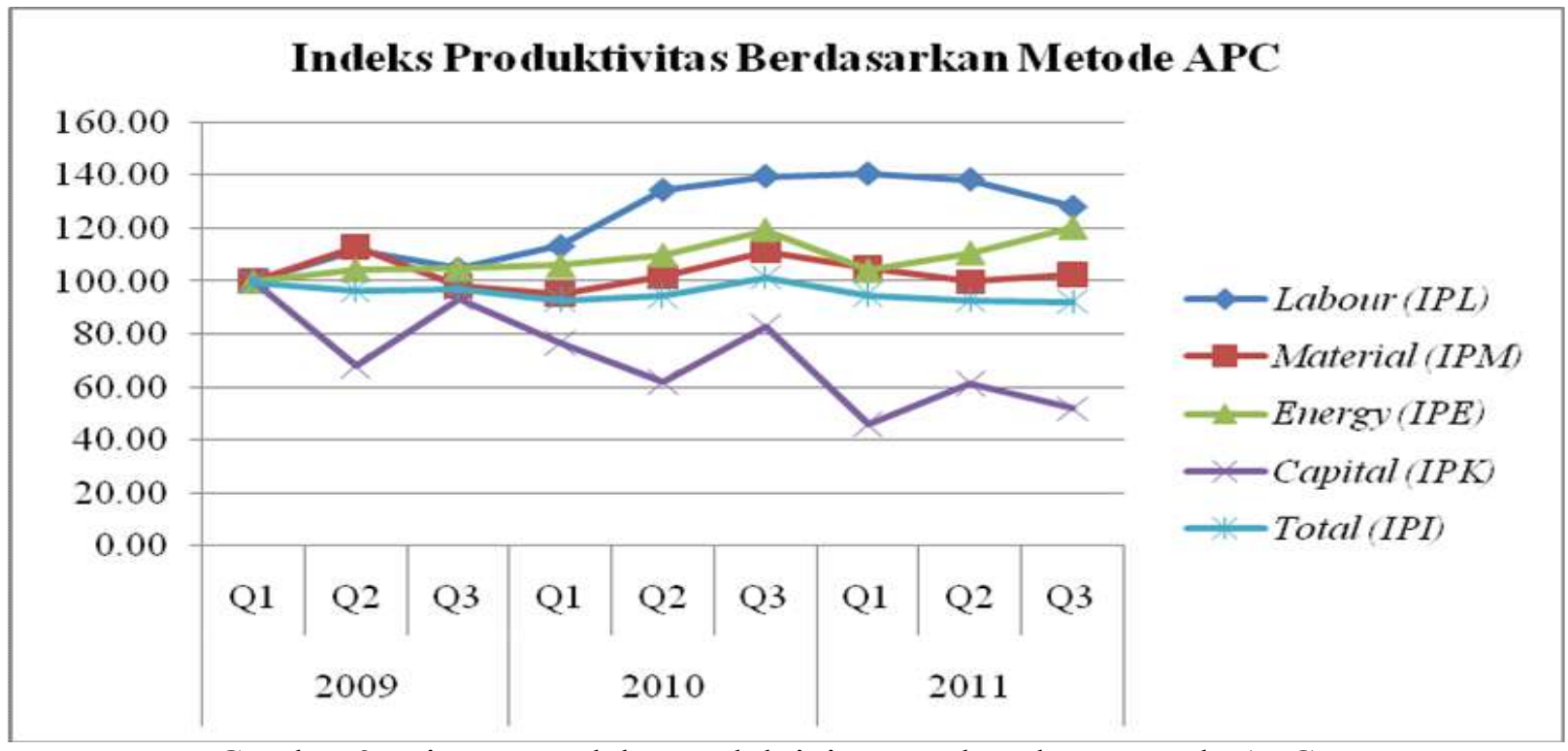

Gambar 3. Diagram Indeks Produktivitas Berdasarkan Metode APC. 
Tabel 8. Indeks Output Berdasarkan Harga yang Berlaku

\begin{tabular}{|c|c|c|c|c|c|c|c|c|}
\hline \multicolumn{2}{|c|}{ Tahun } & Kuartal & \multicolumn{2}{|c|}{$\begin{array}{c}\text { Kain Grey (O) } \\
\text { (Rupiah) }\end{array}$} & \multicolumn{4}{|c|}{$\begin{array}{c}\text { Indeks Output } \\
\text { Labour (L) }\end{array}$} \\
\hline \multirow{3}{*}{\multicolumn{2}{|c|}{2009}} & Q1 & \multicolumn{2}{|c|}{32.035 .871 .652} & \multicolumn{4}{|c|}{1,00} \\
\hline & & Q2 & \multicolumn{2}{|c|}{35.842 .572 .800} & \multicolumn{4}{|c|}{1,12} \\
\hline & & Q3 & \multicolumn{2}{|c|}{34.243 .170 .555} & \multicolumn{4}{|c|}{1,07} \\
\hline \multirow{2}{*}{\multicolumn{2}{|c|}{2010}} & Q1 & \multicolumn{2}{|c|}{35.400 .839 .920} & \multicolumn{4}{|c|}{1,11} \\
\hline & & Q2 & \multicolumn{2}{|c|}{42.036 .080 .742} & \multicolumn{4}{|c|}{1,31} \\
\hline & & Q3 & \multicolumn{2}{|c|}{38.607 .971 .040} & \multicolumn{4}{|c|}{1,21} \\
\hline & 2011 & Q1 & 44.6 & 31.081 .990 & & & 1,39 & \\
\hline & & Q2 & 44.9 & 98.236 .680 & & & 1,40 & \\
\hline & & Q3 & 41.6 & 14.847 .976 & & & 1,30 & \\
\hline & Data & ut Berdasar & in Harga Yang & Berlaku Tahun & In 2009 - & & & \\
\hline Thn & Kuartal & $\begin{array}{c}\text { Labour (L) } \\
\text { (Rupiah) }\end{array}$ & $\begin{array}{c}\text { Material (M) } \\
\text { (Rupiah) }\end{array}$ & $\begin{array}{c}\text { Energy (E) } \\
\text { (Rupiah) }\end{array}$ & $\begin{array}{r}\text { Capita } \\
\text { (Rup }\end{array}$ & $\begin{array}{l}l(\mathrm{C}) \\
\text { ah) }\end{array}$ & & $\begin{array}{l}\text { otal (I) } \\
\text { upiah) }\end{array}$ \\
\hline 2009 & Q1 & 1.986 .920 .000 & 20.443 .782 .149 & 3.259 .401 .979 & 6.345 .7 & 7.524 & 21.7 & 0.670 .243 \\
\hline & Q2 & 1.986 .920 .000 & 20.043 .310 .733 & 3.402 .931 .311 & 10.409 .4 & 10.756 & 71.2 & 3.412 .720 \\
\hline & Q3 & 2.033 .000 .000 & 21.651 .591 .762 & 3.442 .977 .185 & 7.115 .6 & 1.608 & 76.2 & 9.251 .297 \\
\hline 2010 & Q1 & 1.839 .320 .000 & 21.770 .670 .243 & 3.330 .284 .495 & 8.460 .5 & 5.182 & 74.0 & 8.810 .960 \\
\hline & Q2 & 1.839 .320 .000 & 24.103 .156 .104 & 3.632 .281 .012 & 12.461 .3 & 23.626 & 86.6 & 7.162 .732 \\
\hline & Q3 & 1.895 .600 .000 & 23.475 .631 .237 & 3.561 .804 .662 & 9.674 .93 & 5.141 & 83.6 & 6.207 .720 \\
\hline 2011 & Q1 & 2.131 .560 .000 & 24.810 .943 .824 & 4.074 .952 .476 & 17.688 .5 & 78.166 & 90.3 & 0.882 .442 \\
\hline & Q2 & 2.131 .560 .000 & 25.726 .787 .763 & 4.071.674.328 & 13.068 .2 & 14.589 & 44.9 & 8.236 .680 \\
\hline & Q3 & 2.136 .000 .000 & 21.823 .012 .054 & 3.379 .414 .571 & 13.805 .9 & 77.472 & 41.1 & 4.404 .097 \\
\hline$a b$ & 10. Ind & Input Tahun 2 & $2009-2011$ & & & & & \\
\hline & & & Inde & ks Input denga & an Harga ya & ng Ber & laku & \\
\hline & nun & $\sim 0$ & Labour (L) Mc & aterial (M) E & Energy (E) & Capitc & $l(\mathrm{C})$ & Total (I) \\
\hline & 2009 & Q1 & 1,00 & 1,00 & 1,00 & 1, & & 1,00 \\
\hline & & Q2 & 1,00 & 0,98 & 1,04 & 1,6 & & 3,27 \\
\hline & & Q3 & 1,02 & 1,06 & 1,06 & 1,1 & & 3,50 \\
\hline & 2010 & Q1 & 0,93 & 1,06 & 1,02 & 1,3 & & 3,40 \\
\hline & & Q2 & 0,93 & 1,18 & 1,11 & 1, & & 3,98 \\
\hline & & Q3 & 0,95 & 1,15 & 1,09 & 1,5 & & 3,84 \\
\hline & 2011 & Q1 & 1,07 & 1,21 & 1,25 & 2,7 & & 4,15 \\
\hline & & Q2 & 1,07 & 1,26 & 1,25 & $2,($ & & 2,07 \\
\hline & & Q3 & 1,08 & 1,07 & 1,04 & 2,1 & & 1,89 \\
\hline & 11 I d & itabi & hun 2009 - & 11 Per K & & & & \\
\hline & Tahun & Kuarta & $\begin{array}{l}\text { Labour } \\
\text { (IPFL) }\end{array}$ & $\begin{array}{l}\text { Material } \\
\text { (IPFM) }\end{array}$ & $\begin{array}{c}\text { Energy } \\
\text { (IPFE) }\end{array}$ & $\begin{array}{l}\text { Capi } \\
\text { (IPF }\end{array}$ & & $\begin{array}{l}\text { Total } \\
\text { (IPFI) }\end{array}$ \\
\hline & 2009 & Q1 & 100,00 & 100,00 & 100,00 & 100 & & 100,00 \\
\hline & & Q2 & 111,88 & 114,12 & 107,16 & 68,2 & & 34,19 \\
\hline & & Q3 & 104,47 & 100,93 & 101,19 & 95,3 & & 30,51 \\
\hline & 2010 & Q1 & 119,37 & 103,77 & 108,15 & 82,8 & & 32,51 \\
\hline & & Q2 & 141,75 & 111,29 & 117,75 & 66,8 & & 32,96 \\
\hline & & Q3 & 126,32 & 104,95 & 110,28 & 79,0 & & 31,38 \\
\hline & 2011 & Q1 & 129,86 & 114,79 & 111,43 & 49,9 & & 33,58 \\
\hline & & Q2 & 130,93 & 111,62 & 112,44 & 68,2 & & 67,96 \\
\hline & & Q3 & 120,83 & 121,69 & 125,29 & 59,7 & & 68,73 \\
\hline
\end{tabular}




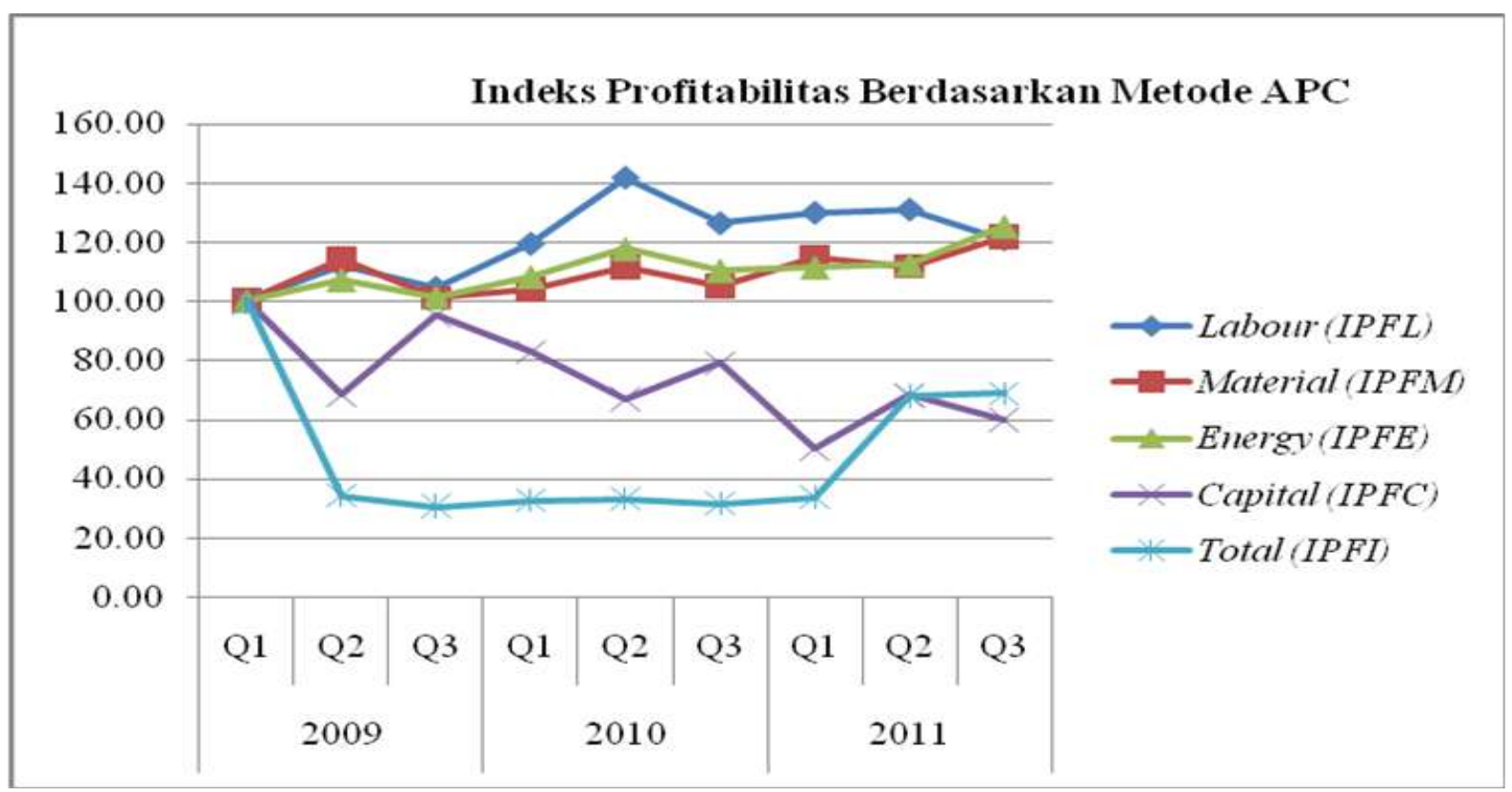

Gambar 4. Diagram Indeks Profitabilitas Berdasarkan Metode APC.

Analisis produktifitas input dilakukan setelah mendapatkan hasil di atas. Pengukuran indeks produktifitas dilakukan dengan menggunakan harga - harga konstan pada periode dasar tahun 2009 kuartal 1 (Q1). Hasilnya adalah seperti yang ditunjukkan dalam Tabel 6 dan Tabel 7, sedangkan gambar 3 menunjukkan pergerakan produktifitas dari periode ke periode.

Indeks produktivitas total input pada PT. Primissima mengalami penurunan sebesar 96,00 berdasarkan nilai input secara parsialnya, diketahui bahwa rasio produktivitas pada input capital semakin menurun pada tiap kuartalnya yaitu rata rata penurunan sebesar 71,40 . Hal ini berarti ada penggunaan capital yang tidak efisien, sedangkan untuk variabel input lainnya mengalami peningkatan. Penurunan nilai produktifitas capital ini dapat disebabkan oleh banyak hal, pengalokasian capital yang kurang tepat sasaran atau pengembangan perusahaan yang menyebabkan penggunaan capital berlebih.

\subsubsection{Analisis Produktifitas Output}

Langkah awal untuk analisis produktifitas output ini adalah menghitung indeks output berdasarkan harga konstan dan hasilnya seperti yang ditunjukkan oleh tabel 8 .
Kemudian dilanjutkan dengan perhitungan indeks output menggunakan harga yang berlaku. Tabel 9 menunjukkan data harga yang berlaku. Tabel 10 menunjukkan hasil perhitungan indeks output berdasarkan harga yang berlaku.

Analisis profitabilitas dapat dilakukan terdahap output yang telah diketahui. Hasilnya adalah seperti yang ditunjukkan oleh tabel 11 dengan pergerakan setiap periodenya seperti yang ditunjukkan oleh gambar 4.

Indeks profitabilitas total input mengalami penurunan rata - rata sebesar 47,98. Hal ini menggambarkan bahwa perusahaan mendapatkan nilai profitabilitas yang tidak baik. Berdasarkan perhitungan profitabilitas secara parsial diketahui adanya peningkatan yang dapat membuat perusahaan memiliki nilai profitabilitas yang baik dengan indeks material bernilai 109,24, selanjutnya indeks energy yaitu 110,41 dan nilai indeks profitabilitas yang paling tinggi dari indeks labour yaitu sebesar 120,60. Dari hal ini dapat diketahui bahwa perusahaan masih bisa mendapatkan material dengan mudah, dan hasil pengolahan dari bahan material dan labour yang baik dapat meningkatkan profitabilitas perusahaan. 
Tabel 12. Indeks Perbaikan Harga Tahun 2009 - 2011 Per Kuartal

\begin{tabular}{ccccccc} 
Tahun & Kuartal & $\begin{array}{c}\text { Labour } \\
\left(\text { IPH }_{\mathbf{L}}\right)\end{array}$ & $\begin{array}{c}\text { Material } \\
\left(\mathbf{I P H}_{\mathbf{M}}\right)\end{array}$ & $\begin{array}{c}\text { Energy } \\
\left(\mathbf{I P H}_{\mathbf{E}}\right)\end{array}$ & $\begin{array}{c}\text { Capital } \\
\left(\text { IPH }_{\mathbf{C}}\right)\end{array}$ & $\begin{array}{c}\text { Total } \\
\left(\text { (IPH }_{\mathbf{I}}\right)\end{array}$ \\
\hline \multirow{2}{*}{2009} & Q1 & 1,00 & 1,00 & 1,00 & 1,00 & 1,00 \\
& Q2 & 1,00 & 1,01 & 1,03 & 1,00 & 0,35 \\
& Q3 & 1,00 & 1,03 & 0,97 & 1,02 & 0,31 \\
& Q1 & 1,05 & 1,09 & 1,02 & 1,08 & 0,35 \\
& Q2 & 1,05 & 1,10 & 1,07 & 1,08 & 0,35 \\
& Q3 & 0,90 & 0,94 & 0,92 & 0,95 & 0,31 \\
& Q1 & 0,92 & 1,09 & 1,07 & 1,09 & 0,35 \\
& Q2 & 0,94 & 1,12 & 1,01 & 1,11 & 0,73 \\
& Q3 & 0,94 & 1,19 & 1,04 & 1,15 & 0,74 \\
\hline
\end{tabular}

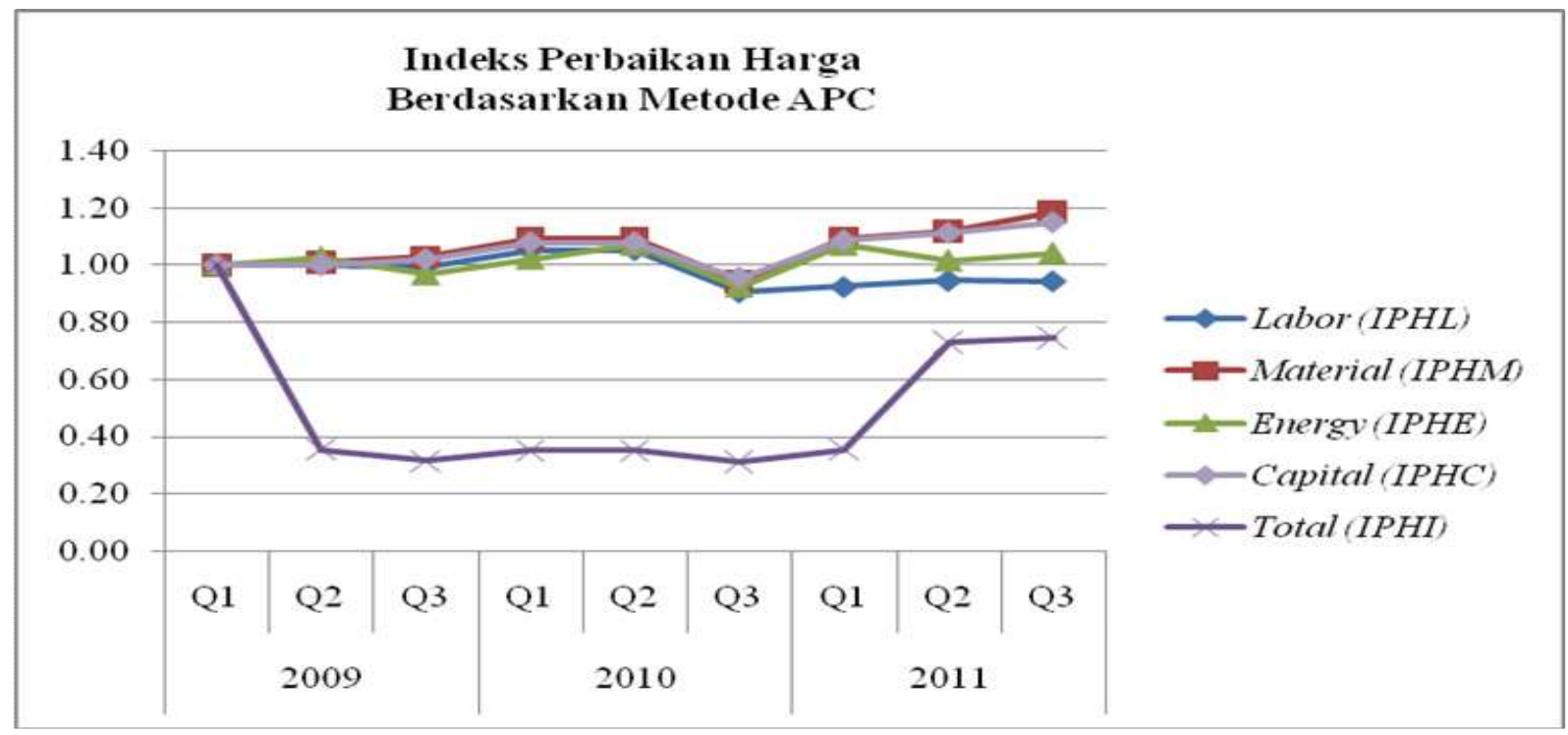

Gambar.5 Diagram Indeks Perbaikan Harga Berdasarkan Metode APC.

\subsubsection{Analisis Indeks Perbaikan Harga}

Analisis berikutnya yang bisa dilakukan adalah mengenai Indeks Perbaikan Harga (IPH) yang pada dasarnya merupakan rasio antara Indeks Profitabilitas (IPF) dengan Produktivitas (IP). Hasil perhitungan IPH adalah seperti yang ditunjukkan oleh tabel 12 dan pergerakan per periodenya seperti yang ditunjukkan oleh gambar 5 .

Indeks perbaikan harga input total rata rata mengalami penurunan 0,50 perkuartalnya. Pada indeks perbaikan harga pada input labour, rata - rata mengalami penurunan sebesar 0,98 per kuartalnya, sedangkan indeks perbaikan harga input material mengalami peningkatan rata - rata 1,06 per kuartal. Dalam indeks perbaikan harga input energy meningkat rata - rata 1,01 per kuartalnya dan juga indeks perbaikan harga input capital meningkat rata - rata 1,05 per kuartalnya. 
Tabel 13 Indeks Produktivitas Faktor Labor Dalam Satu Tahun

\begin{tabular}{lccc}
\hline \multicolumn{1}{c}{ Bulan } & Tahun 2009 & $\begin{array}{c}\text { Indeks Produktivitas Labor } \\
\text { Tahun 2010 }\end{array}$ & Tahun 2011 \\
\hline Januari & 16,99 & 19,21 & 22,23 \\
Februari & 15,05 & 18,83 & 19,37 \\
Maret & 16,77 & 19,04 & 21,62 \\
April & 15,67 & 19,91 & 21,02 \\
Mei & 16,85 & 22,52 & 25,15 \\
Juni & 18,60 & 23,04 & 20,58 \\
Juli & 18,00 & 21,83 & 20,97 \\
Agustus & 18,71 & 24,03 & 17,74 \\
September & 17,49 & 18,32 & 19,32 \\
Oktober & 17,70 & 23,89 & 20,98 \\
Nopember & 16,09 & 17,69 & 18,00 \\
Desember & 16,09 & 21,57 & 19,63 \\
\hline \multicolumn{1}{c}{ Jumlah } & $\mathbf{2 0 4 , 0 3}$ & $\mathbf{2 4 9 , 8 7}$ & $\mathbf{2 4 6 , 6 2}$ \\
\hline
\end{tabular}

Tabel 14 Indeks Produktivitas Faktor Material Dalam Satu Tahun

\begin{tabular}{lccc}
\hline \multicolumn{1}{c}{ Bulan } & Tahun 2009 & $\begin{array}{c}\text { Indeks Produktivitas Material } \\
\text { Tahun 2010 }\end{array}$ & Tahun 2011 \\
\hline Januari & 1,53 & 1,60 & 1,74 \\
Februari & 1,52 & 1,70 & 1,79 \\
Maret & 1,61 & 1,61 & 1,85 \\
April & 1,61 & 1,61 & 1,87 \\
Mei & 1,67 & 1,80 & 1,91 \\
Juni & 2,97 & 1,72 & 1,84 \\
Juli & 1,62 & 1,67 & 1,62 \\
Agustus & 1,45 & 1,78 & 1,62 \\
September & 1,74 & 1,63 & 1,77 \\
Oktober & 1,58 & 1,63 & 1,76 \\
Nopember & 1,59 & 1,79 & 1,77 \\
Desember & 1,44 & 1,57 & 1,87 \\
\hline Jumlah & $\mathbf{2 0 , 3 2}$ & $\mathbf{2 0 , 1 1}$ & $\mathbf{2 1 , 4 1}$ \\
\hline
\end{tabular}


Tabel 15. Indeks Produktivitas Faktor Energy Dalam Satu Tahun

\begin{tabular}{lccc}
\hline \multicolumn{1}{c}{ Bulan } & Tahun 2009 & $\begin{array}{c}\text { Indeks Produktivitas Energy } \\
\text { Tahun 2010 }\end{array}$ & Tahun 2011 \\
\hline Januari & 9,96 & 10,72 & 11,14 \\
Februari & 9,12 & 11,10 & 11,43 \\
Maret & 10,37 & 10,38 & 10,88 \\
April & 9,87 & 10,37 & 10,68 \\
Mei & 10,10 & 10,45 & 12,62 \\
Juni & 11,19 & 12,64 & 10,16 \\
Juli & 10,05 & 11,16 & 10,39 \\
Agustus & 10,81 & 12,12 & 11,10 \\
September & 10,16 & 10,12 & 12,17 \\
Oktober & 9,51 & 11,93 & 11,28 \\
Nopember & 10,30 & 9,78 & 13,06 \\
Desember & 9,88 & 11,39 & 12,98 \\
\hline Jumlah & $\mathbf{1 2 1 , 3 1}$ & $\mathbf{1 3 2 , 1 6}$ & $\mathbf{1 3 7 , 8 8}$ \\
\hline
\end{tabular}

Tabel 16. Indeks Produktivitas Faktor Capital Dalam Satu Tahun

\begin{tabular}{lccc}
\hline \multicolumn{1}{c}{ Bulan } & \multicolumn{3}{c}{$\begin{array}{c}\text { Indeks Produktivitas Capital } \\
\text { Tahun 2010 }\end{array}$} \\
\hline Januari & 5,31 & 4,37 & Tahun 2011 \\
Februari & 6,06 & 3,74 & 3,45 \\
Maret & 4,46 & 4,37 & 3,32 \\
April & 4,71 & 4,31 & 3,11 \\
Mei & 4,13 & 3,29 & 3,09 \\
Juni & 1,92 & 3,37 & 2,79 \\
Juli & 4,39 & 3,75 & 3,25 \\
Agustus & 6,02 & 3,17 & 4,22 \\
September & 3,73 & 4,30 & 4,22 \\
Oktober & 4,84 & 3,82 & 3,31 \\
Nopember & 4,73 & 3,53 & 3,39 \\
Desember & 7,14 & 4,40 & 3,29 \\
\hline Jumlah & $\mathbf{5 7 , 4 4}$ & $\mathbf{4 6 , 4 3}$ & 2,96 \\
\hline
\end{tabular}

Tabel 17. Produktifitas Total Tahun 2009

\begin{tabular}{lcc}
\hline \multicolumn{1}{c}{ Variabel } & Rata-rata Logaritma & Elastisitas \\
Input Labour & 20,03 & 0,45 \\
Input Material & 22,35 & $-0,15$ \\
Input Energy & 20,55 & 0,48 \\
Input Capital & 21,34 & 0,13 \\
\hline \multicolumn{2}{c}{ Elastisitas Total ( $\beta$ total) } \\
\hline
\end{tabular}


Tabel18. Produktivitas Total Tahun 2010

\begin{tabular}{lcc}
\hline \multicolumn{1}{c}{ Variabel } & Rata-rata Logaritma & Elastisitas \\
\hline Input Labour & 19,96 & 1,36 \\
Input Material & 22,47 & $-0,21$ \\
Input Energy & 20,59 & $-1,67$ \\
Input Capital & 21,64 & 0,18 \\
\hline & Elastisitas Total ( $\beta$ total) & $\mathbf{- 0 , 3 4}$ \\
\hline
\end{tabular}

Tabel 19 Produktivitas Total Tahun 2011

\begin{tabular}{lcc}
\hline \multicolumn{1}{c}{ Variabel } & Rata-rata Logaritma & Elastisitas \\
\hline Input Labour & 20,09 & 0,47 \\
Input Material & 22,53 & $-0,10$ \\
Input Energy & 20,67 & 0,50 \\
Input Capital & 21,91 & 0,41 \\
\hline & Elastisitas Total ( $\beta$ total) & $\mathbf{1 , 2 8}$ \\
\hline
\end{tabular}

Tabel 20. Indeks - indeks Produktifitas Selama 3 Periode

\begin{tabular}{|c|c|c|c|c|c|c|c|c|c|}
\hline \multirow{2}{*}{$\begin{array}{c}\text { Ket } \\
\beta\end{array}$} & \multirow{2}{*}{$\begin{array}{c}\text { Jenis Input } \\
\text { Variabel }\end{array}$} & \multirow{2}{*}{$\begin{array}{c}\text { Periode } \\
\text { Dasar }\end{array}$} & \multicolumn{2}{|c|}{ Produktivitas } & \multirow{2}{*}{$\begin{array}{c}\text { Periode } \\
\text { Dasar }\end{array}$} & \multicolumn{2}{|c|}{ Indeks } & \multicolumn{2}{|c|}{$\begin{array}{c}\text { Perubahan Indeks } \\
\%\end{array}$} \\
\hline & & & $\begin{array}{c}\text { Periode } \\
2010\end{array}$ & $\begin{array}{l}\text { Periode } \\
2011\end{array}$ & & $\begin{array}{l}\text { Periode } \\
2010\end{array}$ & $\begin{array}{l}\text { Periode } \\
2011\end{array}$ & $\begin{array}{l}\text { Periode } \\
2010\end{array}$ & $\begin{array}{l}\text { Periode } \\
2011\end{array}$ \\
\hline & & 2 & 3 & 4 & 5 & $6=(3 / 2)$ & $7=(4 / 2)$ & $8=(6-5)$ & $\begin{array}{c}9=(7- \\
5)\end{array}$ \\
\hline$\beta 1$ & Labour & 0,45 & 1,36 & 0,47 & 100,0 & 302,2 & 104,44 & +202 & $+4,44$ \\
\hline$\beta 2$ & Material & $-0,15$ & $-0,21$ & $-0,10$ & 100,0 & 140 & 66,6 & +40 & $-33,4$ \\
\hline$\beta 3$ & Energy & 0,48 & $-1,67$ & 0,50 & 100,0 & $-347,9$ & 104,16 & $-248,9$ & $+4,16$ \\
\hline$\beta 4$ & Capital & 0,13 & 0,18 & 0,41 & 100,0 & 138,5 & 315,38 & $+38,46$ & +15.38 \\
\hline
\end{tabular}

Tabel 21. Fungsi Cobb-Douglas Tahun 2009

\begin{tabular}{|c|c|c|c|c|c|c|}
\hline \multicolumn{7}{|c|}{ Coefficients $^{\mathrm{a}}$} \\
\hline & \multirow[b]{2}{*}{ Model } & \multicolumn{2}{|c|}{ Unstandardized Coefficients } & \multirow{2}{*}{$\begin{array}{c}\text { Standardized } \\
\text { Coefficients } \\
\text { Beta } \\
\end{array}$} & \multirow[b]{2}{*}{$\mathbf{T}$} & \multirow[b]{2}{*}{ Sig. } \\
\hline & & B & Std. Error & & & \\
\hline \multirow{5}{*}{1} & (Constant) & 17.893 & 14.765 & & 1.212 & .265 \\
\hline & Labour & -.549 & .767 & -.121 & -.717 & .497 \\
\hline & Material & .062 & .084 & .161 & .741 & .483 \\
\hline & Energi & .613 & .237 & .492 & 2.591 & .036 \\
\hline & Capital & .093 & .026 & .728 & 3.543 & .009 \\
\hline
\end{tabular}




\subsubsection{Analisis Produktifitas \\ Menggunakan Cobb - Douglas}

Untuk bisa melakukan pengukuran dengan fungsi Cobb-Douglas maka data yang dikumpulkan perlu ditransformasikan dalam bentuk logaritma natural $(L n)$. tabel 13 sampai dengan tabel 16 menunjukkan hasil perhitungan produktifitas setiap faktor produksi sedangkan hasil transformasi setiap faktor produksi menjadi $L n$ adalah ditunjukkan oleh tabel 17 sampai dengan tabel 18.

Tabel 20 berikut ini menunjukkan indeks produktifitas dan perubahan produktifitas yang terjadi di industri obyek penelitian.

\section{a. Dependent Variable : Produksi}

Sumber : (Olahan, 2015)

Sehingga, persamaan Regresi dan CobbDouglas tahun 2009 adalah sebagai berikut :

$$
\begin{aligned}
& \text { Ln } O=17,893+-0,549 \mathrm{LnL}+0,062 \mathrm{LnM} \\
& +0,613 \mathrm{LnE}+0,093 \mathrm{LnC} \\
& \begin{array}{l}
O=\mathrm{e}^{17,893} \mathrm{~L}^{-0,549} \mathrm{M}^{0,062} \mathrm{E}^{0,613} \mathrm{C}^{0,093} \\
O \quad=58.997 .167,96 \mathrm{~L}^{-0,549} \mathrm{M}^{0,062} \mathrm{E}^{0,613} \\
\quad \mathrm{C}^{0,093}
\end{array}
\end{aligned}
$$

Nilai Return to Scale (RTS) tahun 2009 adalah sebagai berikut :

RTS $=-0,549+0,062+0,613+0,093=$ 0,219

Persamaan Regresi dan Cobb-Douglas tahun 2010 adalah sebagai berikut :

Ln $O=2,140+-0,032 \mathrm{LnL}+0,595 \mathrm{LnM}+$ $0,114 \mathrm{LnE}+0,267 \mathrm{LnC}$

$O=\mathrm{e}^{2,140} \mathrm{~L}^{-0,032} \mathrm{M}^{0,595} \mathrm{E}^{0,114} \mathrm{C}^{0,267}$

$O=8,499 \mathrm{~L}^{-0,032} \mathrm{M}^{0,595} \mathrm{E}^{0,114} \mathrm{C}^{0,267}$

Nilai RTS tahun 2010 adalah sebagai berikut

RTS $=-0,032+0,595+0,114+0,267$

RTS $=0,944$

Persamaan Regresi dan Cobb-Douglas tahun 2011 adalah sebagai berikut :

$$
\begin{aligned}
& \text { Ln } O=17,404+-0,781 \mathrm{LnL}+0,602 \mathrm{LnM} \\
& +0,063 \mathrm{LnE}+0,298 \mathrm{C} \\
& \begin{array}{l}
O=\mathrm{e}^{17,404} \mathrm{~L}^{-0,781} \mathrm{M}^{0,602} \mathrm{E}^{0,063} \mathrm{C}^{0,298} \\
O \quad=36.179 .393,57 \mathrm{~L}^{-0,781} \mathrm{M}^{0,602} \mathrm{E}^{0,063} \\
\quad \mathrm{C}^{0,298}
\end{array}
\end{aligned}
$$

Nilai RTS tahun 2011 adalah sebagai berikut

$$
\begin{aligned}
\text { RTS } & =-0,781+0,602+0,063+0,298 \\
& =0,182
\end{aligned}
$$

Indeks efisiensi produksi dari PT. Primissima pada tahun 2009 adalah sebesar koefisien intersep yaitu 58.997.167,96. Sedangkan indeks efisiensi produksi PT. Primissima pada tahun 2010 adalah 8,499 dan pada tahun 2011 sebesar 36.179.393,57. Apabila dibandingkan indeks efisiensi produksi tahun 2009 dengan 2010 adalah $8,499 / 58.997 .167,96=1,44$ Hal ini menunjukkan bahwa efisiensi produksi PT. Primissima tahun 2010 mengalami peningkatan 44\% dari pada tahun 2009. Apabila dibandingkan indeks efisiensi produksi tahun 2009 dengan 2011 adalah 36.179.393,57/58.997.167,96 = 0,61 Hal ini menunjukkan bahwa efisiensi produksi PT. Primissima tahun 2011 mengalami menurun $39 \%$ dari pada tahun 2009 .

\subsection{Perbandingan Tingkat Indeks Produktifitas}

Pengukuran tingkat produktivitas menggunakan metode APC dihitung dari tingkat indeks produktifitas, indeks profitabilitas, dan indeks perbaikan harga. Pengukuran produktifitas dengan metode APC (American Productivity Center) menunjukkan bahwa pada tahun 2009 hinga tahun 2011 PT. Primissima mengalami penurunan sebesar 96,00 berdasarkan nilai input secara persialnya pada tiap kuartalnya. Sedangkan pengukuran tingkat produktifitas menggunakan metode Cobb-Douglas dihitung berdasarkan tingkat produktifitas dan perhitungan dilakukan menggunakan persamaan regresi. Berdasarkan hasil pendekatan fungsi Cobb-douglas terlihat 
bahwa pada tahun 2010 PT. Primissima mengalami peningkatan $44 \%$ dari perbandingan nilai indeks efisiensi, namun pada tahun 2011 mengalami penurunan $39 \%$ sesuai dari periode dasar tahun 2009 terhadap 2011.

\section{KESIMPULAN DAN SARAN}

Analisis produktifitas menggunakan APC menunjukkan produktifitas setiap faktor produksi sehingga usaha perbaikan produktifitas dapat dilakukan untuk setiap faktor. Pengukuran produktiftas menggunakan fungsi produksi CobbDouglas menunjukkan produktifitas berdasarkan output dan juga menghasilkan persamaan produksi yang dapat digunakan sebagai prediksi jumlah output di masa yang akan datang.

Dari hasil analisis yang telah dilakukan, maka dapat disarankan bahwa PT. Primissima perlu melakukan perbaikan dari sektor tenaga kerja, meningkatkan kemampuan tenaga kerja, dan dilakukan pengurangan jam lembur kerja karena adanya perbaikan harga. Dalam sektor energi perlu dilakukan perencanaan pemakaian energi agar penggunaan listrik dan bahan bakar bisa lebih efisien dan tidak mengalami pemborosan. Selanjutnya pada sektor modal sebaiknya dilakukan perencanaan atau perancangan pengeluaran modal kerja dengan menggunakan operasional produksi yang optimal sehingga penggunaan dan aliran modal dapat dilakukan secara efisien. Peningkatan produktivitas juga perlu dilakukan sektor material dengan cara mengendalikan bahan baku agar tidak terjadi pemborosan sehingga bahan baku akan digunakan dengan lebih efisien.

\section{DAFTAR PUSTAKA}

Gaspersz, V. Manajemen Produktivitas Total. Jakarta : PT. Gramedia Pustaka Utama, 1998.

Heri Suliantoro, Ary Arvianto dan Purnomo Setyo Kusumo. Analisa dan evaluasi produktivitas melalui pendekatan the Amerian Productivity Center model (APC). Semarang: Universitas Diponegoro, 2006.

Masharyono. Analisis pengukuran produktivitas dengan model The American Productivity Center (APC) dan Marvin E. Mundel. Yogyakarta : Universitas Islam Negeri Sunan Kalijaga, 2012.

Sutrisno dan Ferry Suzanto. Perencanaan peningkatan produktivitas proses fabrikasi dengan pendekatan fungsi produksi Cobb-Douglas. Surabaya: Institut Teknologi Adhi Tama, 2012.

Yuliastuti Ramadhani. Analisis efisiensi, skala dan elastisitas produksi dengan pendekatan Cobb-Douglas dan regresi berganda. Yogyakarta: Institut Sains dan Teknologi AKPRIND, 2011. 